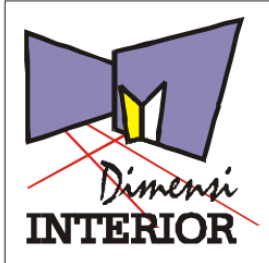

http://dimensiinterior.petra.ac.id

\title{
Identifikasi Penerapan Biophilic Design pada Interior Fasilitas Pendidikan Tinggi
}

\author{
Kay Kalonica | Yusita Kusumarini | Anik Rakhmawati \\ Program Studi Desain Interior, Universitas Kristen Petra, Surabaya \\ Email: kkalonica@gmail.com
}

\begin{abstract}
ABSTRAK
Pelajar, pengajar, dan staf pendidikan membutuhkan suatu fasilitas pendidikan tinggi yang dapat meningkatkan kinerja dan kenyamanan pengguna. Salah satu pendekatan desain yang dapat memenuhi kebutuhan tersebut adalah biophilic design. Biophilic design dapat meningkatkan produktivitas dan kreatifitas serta menurunkan tingkat stres. Penerapan biophilic design dalam interior fasilitas pendidikan tinggi perlu diteliti lebih lanjut karena minimnya informasi tentang hal ini. Permasalahan yang dapat dirumuskan adalah bagaimana identifikasi penerapan biophilic design dalam interior fasilitas pendidikan tinggi serta rekomendasi terapan biophilic design pada interior gedung P1 dan P2 Universitas Kristen Petra. Penelitian kualitatif ini menggunakan pendekatan metode research through design yang mengadopsi metode dan keterampilan peneliti yang sifatnya fleksibel. Hasil penelitian ini mengungkapkan bahwa identifikasi penerapan biophilic design pada interior fasilitas pendidikan tinggi dapat dilakukan dengan menerapkan semua 14 pola biophilic design. Rekomendasi terapan pola biophilic design pada objek studi kasus Gedung P1 dan P2 Universitas Kristen Petra telah disimulasikan dengan menerapkan semua 14 pola biophilic design pada interior ruang melalui ide-ide sketsa konseptual.
\end{abstract}

Kata Kunci: Biophilic design, fasilitas pendidikan, interior, alam.

\section{ABSTRACT}

Students, teachers, and education staff need a higher education facility that can improve user performance and convenience. One of the design approaches that can fulfill these needs is biophilic design. Biophilic design can improve productivity and creativity as well as decrease stress levels. Application of biophilic design in the interior of higher education facilities needs to be studied further because of the lack of information about this topic. The problems that can be formulated are how biophilic design identification can be applied in the interior of higher education facilities and recommendation of biophilic design application on the case study of P1 and P2 building of Petra Christian University. This qualitative research used 'research through design' method that adopts researcher's flexible method and skill. The results of this study say that the identification of the biophilic design application in the interior of higher education facilities can be done by applying all 14 biophilic design patterns. Biophilic design recommendations on the case study objects P1 and P2 building of Petra Christian University have been simulated by applying all 14 biophilic design patterns to the interior space through conceptual sketch ideas.

Keywords: Biophilic design, educational facilities, interior, nature.

\section{PENDAHULUAN}

Pendidikan menjadi faktor penting yang menentukan kemajuan suatu negara di masa kini. Tidak terkecuali pendidikan di perguruan tinggi yang selalu memegang peranan sentral pada pembangunan bangsa dan negara. Kegiatan belajar dan mengajar ini perlu ditunjang fasilitas pendidikan yang baik sehingga proses belajar dapat berjalan secara kondusif. Sayangnya di Indonesia masih banyak perguruan tinggi yang memiliki sarana dan prasarana kurang memadai. Arsitek dan desainer interior memegang peran penting dalam menciptakan lingkungan perguruan tinggi yang berkualitas.
Salah satu upaya untuk meningkatkan kenyamanan dan kinerja dalam fasilitas pendidikan tinggi adalah dengan menghadirkan alam ke lingkungan belajar. Alam dapat mendukung suasana belajar karena manusia cenderung untuk memiliki koneksi dengan alam baik secara sadar maupun tidak sadar. Penerapan konsep biophilia di bidang interior dan arsitektur dikenal dengan istilah biophilic design yang menunjukkan pentingnya manusia berhubungan dengan alam untuk bertahan hidup di era modern [1]. Manfaat dari penerapan biophilic design di sekolah dapat ditunjukkan dari studi kasus terdahulu antara lain: meningkatkan produktivitas, menurunkan tingkat stres, hingga meningkatkan tingkat pemulihan tubuh manusia [2]. Beberapa bangunan yang 
menerapkan biophilic design juga dapat ikut serta dalam penghematan energi karena bangunan tersebut memanfaatkan alam seefisien mungkin seperti penggunaan pencahayaan dan penghawaan alami, pemanfaatan tanaman dalam ruang, serta penggunaan aliran air.

Penerapan biophilic design terutama dalam interior perguruan tinggi menarik untuk diteliti karena minimnya informasi yang menunjukkan penerapan pattern biophilic design dalam interior perguruan tinggi. Penjabaran mengenai biophilic design selama ini berfokus pada desain arsitektur saja bukan pada interiornya. Hasil analisis yang dilakukan diharapkan dapat menjadi guidelines untuk perancangan interior perguruan tinggi dengan pendekatan biophilic design yang bermanfaat bagi desainer interior

Berdasarkan fenomena di atas, maka masalah dapat dirumuskan sebagai berikut:

1) Bagaimana menerapkan biophilic design dalam interior fasilitas pendidikan tinggi?

2) Bagaimana rekomendasi penerapan biophilic design pada interior gedung P1 dan P2 Universitas Kristen Petra?

Tujuan penelitian dari rumusan masalah di atas yaitu:

1) Menguraikan bentuk aplikasi biophilic design pada interior fasilitas pendidikan tinggi.

2) Memberikan rekomendasi penerapan biophilic design pada interior gedung P1 dan P2 Universitas Kristen Petra.

\section{METODE PENELITIAN}

Metode yang digunakan dalam penelitian kualitatif ini menggunakan pendekatan metode research through design. Pendekatan ini bersifat fleksibel karena mengadopsi metode, alat, dan keterampilan peneliti yang berbeda dari pendekatan riset lain dengan metode dan prosedur analisis yang rigid [3]. Subyektivitas peneliti dalam pendekatan penelitian desain ini tidak dapat dihindari. Pemahaman dari eksplorasi obyek desain perlu diperhatikan karena harus bersifat eksplisit, dapat didiskusikan, dapat dialihkan, dan dapat diakumulasi [3]. Luaran dari penelitian ini berupa peluang dan contoh terapan desain yang dapat dimanfaatkan oleh orang lain dalam mendesain. Penelitian ini dapat dibagi menjadi tiga tahap yaitu pengumpulan data, analisis data, dan penyajian analisis data.

\section{A. Metode Pengumpulan Data}

Peneliti akan menggunakan metode literature review yang dilakukan dengan studi literatur mengenai teori biophilic design dalam interior dan standar yang dibutuhkan dalam merancang interior fasilitas pendidikan. Pengumpulan data literatur pada penelitian ini diperoleh melalui buku dan jurnal penelitian yang pernah dilakukan sebelumnya baik melalui media online maupun media cetak.

\section{B. Metode Analisis Data}

Metode komparasi dan deskriptif kualitatif dilakukan dengan cara menganalisis biophilic design yang dibandingkan dengan standar desain interior fasilitas pendidikan sehingga didapatkan identifikasi terapan biophilic design dalam interior fasilitas pendidikan tinggi. Hasil identifikasi ini digunakan sebagai acuan dalam memberi rekomendasi terapan biophilic design dalam interior pada objek studi kasus yaitu gedung P1 dan P2 Universitas Kristen Petra.

\section{Metode Penyajian Analisis Data}

Hasil analisis ditulis dalam sebuah laporan penelitian yang berisi kutipan data yang menggambarkan penelitian yang telah dilakukan [4]. Peneliti mencari bentuk penerapan teori dengan mendeskripsikan gambar elemen interior dalam fasilitas pendidikan yang sesuai dengan kategori biophilic design. Rekomendasi terapan pada objek studi kasus juga dilakukan dengan cara membuat sketsa pada foto ruang.

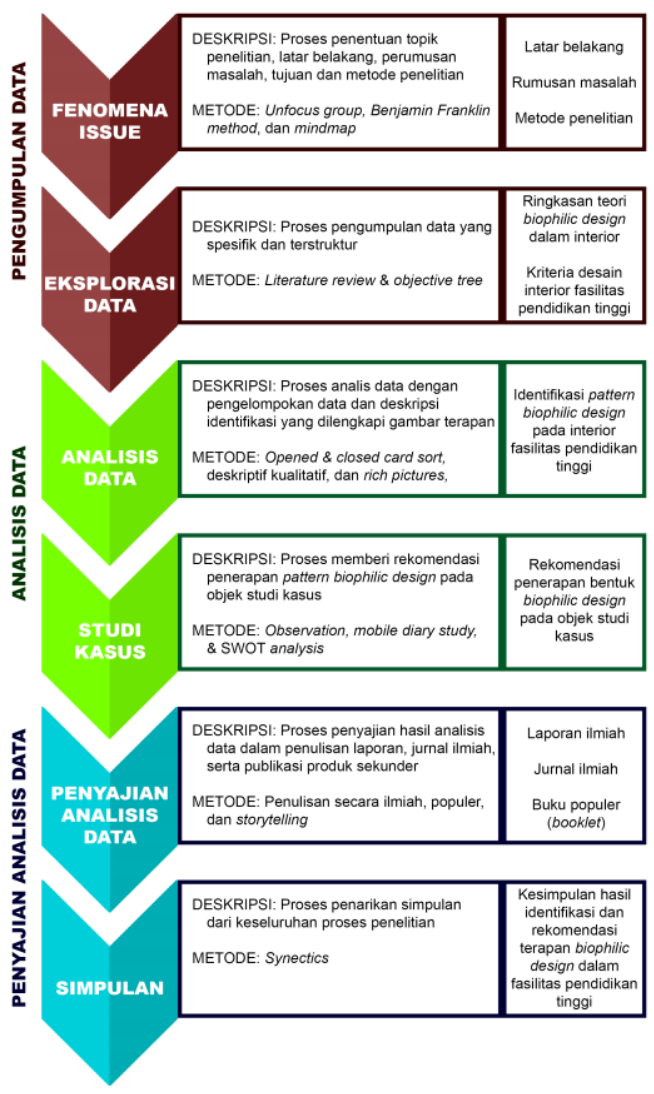

Gambar 1. Alur pola pikir. Sumber: dokumen pribadi

\section{LANDASAN TEORI}

A.Teori Biophilic Design dalam lingkup Desain Interior

Menurut Amjad Almusaed, penerapan konsep biophilic design bukan hanya sebatas membuat sebuah bangunan menjadi bangunan "hijau" dengan hanya memberi konsep tanaman di bangunannya. Konsep ini meminimalisir dampak negatif kehidupan perkotaan dalam skala mikro lokal agar manusia dapat meningkatkan kenyamanan dan kesehatan [5].

Biophilic design memfasilitasi interaksi timbal balik antara manusia dengan alam dan sistem kehidupan. Tujuan biophilic design antara lain menciptakan ruang restoratif dan dapat memulihkan fisik dan psikologis manusia, menyehatkan sistem syaraf dan menampilkan 
daya hidup yang estetik [6]. Berikut ini merupakan penjelasan penerapan 14 pattern biophilic design dalam lingkup desain interior [7]:

\section{1) Visual connection with nature}

Pola yang mengandalkan indera pengelihat dalam merasakan ruang yang berhubungan dengan alam baik secara langsung dan tidak langsung.

\section{2) Non-visual connection with nature}

Pola yang mengandalkan indera pendengar, pencium, peraba, dan perasa dalam merasakan ruang yang berhubungan dengan alam secara multi sensory.

\section{3) Non-rhytmic sensory stimuli}

Pola berkaitan dengan alam yang bersifat acak dan berlangsung sebentar sehingga tidak disadari oleh pengguna ruang tetapi dapat menciptakan suasana yang segar, menarik, dan semangat

\section{4) Thermal and airflow variability}

Pola yang berkaitan dengan pegerakan udara, suhu, dan kelembapan dengan sifat dinamis dan bervariasi pada interior menyerupai kondisi asli di alam

\section{5) Presence of water}

Pola yang meletakkan unsur air dalam ruang untuk memberikan suasana nyaman dan menenangkan sehingga memberi dampak positif terhadap pengguna ruang

\section{6) Dynamic and diffuse lighting}

Pola yang berkaitan dengan pergerakan cahaya alami karena perbedaan waktu yang bersifat dinamis dan menyebar dalam ruang sehingga timbul kontras area terang dan gelap

\section{7) Connection with natural system}

Pola yang menghubungkan interior dengan sistem alam yang selalu berubah agar pengguna ruang dapat berinteraksi dengan alam

\section{8) Biomorphic forms and patterns}

Pola yang meniru atau menstilasi bentuk alam dalam bentuk dan motif untuk elemen pembentuk dan pengisi ruang untuk menghandirkan suasana alam

\section{9) Material Connection with Nature}

Pola yang menggunakan material alami yang mengalami perubahan dari waktu ke waktu sehingga dapat merefleksikan lingkungan lokal

\section{0) Complexity and order}

Pola yang menerapkan bentuk simetri dan geometri yang berulang dengan skala yang sama atau berbeda sehingga individu dapat lebih memahami ruang

\section{1) Prospect}

Pola yang memberikan pandangan luas, terbuka, dan terang pada ruang agar pengguna dapat merasakan keberagaman ruang

\section{2) Refuge}

Pola yang membuat area tertutup atau membatasi pandangan dari luar area agar pengguna dapat merasa aman dan terlindungi

\section{3) Mystery}

Pola yang memberikan rasa kagum dan ingin tahu akan sensasi yang dirasakan dalam ruang seperti pergerakan dinamis dan perubahan dari waktu ke waktu

\section{4) Risk \& Peril}

Pola yang memberikan rasa bahaya atau ancaman tetapi tetap merasa terlindungi agar pengguna ruang dapat meningkatkan keingintahuan, kewaspadaan, dan kekaguman

\section{B. Kriteria Desain Interior Fasilitas Pendidikan Tinggi}

Menurut peraturan menteri pendidikan nasional nomor 24 tahun 2007, untuk menjamin terwujudnya tujuan pelaksanaan pembelajaran dalam pendidikan nasional diperlukan adanya sarana dan prasarana yang memadai [8]. Fasilitas pendidikan tersebut harus memenuhi ketentuan minimum yang ditetapkan. Cara penyusunan kriteria desain interior fasilitas pendidikan tinggi dalam penelitian ini didasarkan pada sembilan elemen desain interior menurut [9]. Berikut kriteria desain interior fasilitas pendidikan tinggi:

\section{1) Lingkungan (Environment)}

Desain bangunan fasilitas pendidikan tinggi perlu mempertimbangkan lingkungan sekitar yang dapat mendukung kesejahteraan pengguna ruang. Lahan kampus perguruan tinggi perlu terhindar dari potensi bahaya yang mengancam kesehatan dan keselamatan jiwa, pencemaran air, udara, dan kebisingan [10]. Desainer juga perlu mementingkan fungsi bangunan, kondisi lingkungan sekitar, memberikan kepuasan estetika, dan menggali potensi yang ada di sekitar site.

\section{2) Ruang (Space)}

Desain interior fasilitas pendidikan tinggi dapat membuat pengguna ruang memiliki pandangan luas, rapi dan terang sehingga fungsi ruang mudah diingat [11]. Area baca, ruang kelas, serta ruang dosen membutuhkan suasana tenang. Suasana hangat juga perlu dihadirkan dalam ruang yang berfungsi sebagai area berkumpul dan beristirahat seperti kantin, lounge, dan student center.

\section{3) Pencahayaan (Light)}

Perguruan tinggi membutuhkan pencahayaan yang tepat di berbagai ruang sesuai aktivitas pengguna. Pemanfaatan sinar matahari digunakan sebagai ambient light. Desain pencahayaan tidak hanya memperhatikan pencahayaan di siang hari, tetapi juga berorientasi pada malam hari karena sebagian pengguna ruang dalam perguruan tinggi melakukan aktivitas hingga malam hari. Pencahayaan juga dapat menjaga keamanan di lingkungan universitas. Keseimbangan antara estetika visual dan keamanan perlu dijaga untuk mencapai desain yang optimal [11]. 


\section{4) Bidang Pijakan (Ground Plane)}

Sebenarnya perguruan tinggi tidak memiliki ketentuan khusus mengenai bentuk dan material lantai. Pertimbangan penting mengenai bentuk, lokasi dan jumlah tangga adalah kemudahan, keamanan, keselamatan, dan kesehatan pengguna [10]. Bangunan bertingkat lebih dari empat lantai dilengkapi dengan elevator. Penggunaan material dan bentuk lantai menyesuaikan kebutuhan aktivitas masing-masing ruang.

\section{5) Pelingkup (Enclosure)}

Bangunan perguruan tinggi harus memenuhi beberapa persyaratan, antara lain: bangunan mampu meredam getaran dan kebisingan yang mengganggu kegiatan pembelajaran, setiap ruangan dilengkapi dengan jendela, pengaturan penghawaan serta tingkat pencahayaan yang memadai, dapat dikunci dengan baik saat tidak digunakan, dan pemeliharaan secara rutin [10].

\section{6) Pendukung (Support)}

Beragam perabot dapat mengakomodasi kegiatan pengguna perpusatakaan seperti kursi, arm chair, sofa, bangku, dan tempat kerja individual. Ruang kelas dilengkapi kursi dengan alas kerja dan dapat dilipat sehingga mudah diatur posisinya. Kursi pada ruang laboratorium, lobby, kantin, dan student center bersifat fleksibel, mudah dipindah dan disimpan sesuai kebutuhan aktivitas [11].

7) Pemajang, Penyimpan, dan Permukaan Kerja (Display, Storage, and Worksurface)

Elemen interior untuk memajang, menyimpan, dan alas kerja dapat dibuat dalam satu bentuk perabot multi fungsi misalnya meja belajar yang dilengkapi dengan rak pajangan dan penyimpan. Pemilihan bentuk dan peletakkan furnitur dapat dilakukan melalui tiga tahap yaitu: mengukur volume kebutuhan dan ruang yang tersedia, menyesuaikan sirkulasi dan dinding tempat mebel akan diletakkan, dan mempertimbangkan fungsi sebagai penyeimbang atau vocal point [11].

\section{8) Dekorasi (Decoration)}

Lukisan dinding atau warna mencolok dapat menunjukan arah atau menandakan area ruang. Dekorasi juga memberi kesan dinamis dan hangat pada ruang [11].

\section{9) Informasi (Information)}

Signage dan kode warna diperlukan untuk menambah petunjuk visual tetapi tidak terlalu banyak karena dapat membingungkan pengguna ruang. Informasi dalam gedung perguruan tinggi biasanya berupa denah nama ruang dalam sebuah gedung dan hubungannya dengan gedung lain. Setiap ruang juga diberi tanda nomor, nama, lokasi gedung dan lantai ruang yang dapat diganti dengan mudah karena fungsi ruang mungkin berganti. Bangunan juga dilengkapi peringatan bahaya dan penunjuk arah yang jelas untuk akses evakuasi termudah [11].

\section{IDENTIFIKASI TERAPAN BIOPHILIC DESIGN PADA INTERIOR FASILITAS PENDIDIKAN TINGGI}

Hasil identifikasi ini berisi deskripsi pengertian, deskripsi aplikasi elemen interior, dan gambar yang dapat mewakili aplikasi elemen interior. Perlu diperhatikan bahwa pola biophilic design tidak dapat berdiri sendiri. Pola-pola ini dapat berhubungan satu dengan yang lain sehingga bentuk aplikasinya terlihat mirip bahkan sama. Hal ini bergantung pada cara desainer menekankan pola yang akan diaplikasikan dalam menciptakan suasana ruang yang memberikan pengalaman biophilia. Berikut ini identifikasi terapan dari 14 pola biophilic design dalam interior fasilitas pendidikan tinggi:

\section{1) Visual connection with nature}

Pola ini menekankan pada pemandangan atau view dari dalam ruang fasilitas pendidikan tinggi baik secara langsung maupun tidak langsung. Kehadiran alam secara langsung dalam ruang dilakukan misalnya memanfaatkan taman dalam ruang, green wall, atau fosil hewan pada perabot. Gambar dan lukisan alam serta stilasi bentuk alam juga dapat dimanfaatkan sebagai penghubung pengguna dengan alam secara tidak langsung.
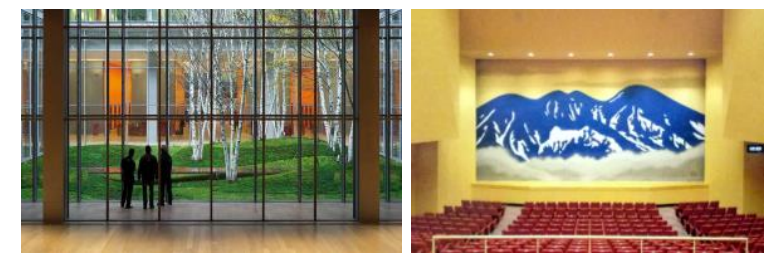

Gambar 2. Contoh penerapan pattern visual connection with nature (kiri) secara langsung dan (kanan) tidak langsung. Sumber: http://pinterest.com

Pola ini dapat diterapkan pada semua elemen interior hampir di seluruh ruang fasilitas pendidikan. Ruang-ruang yang perlu dijaga tetap kering seperti area koleksi perpustakaan dan ruang komputer tidak dapat menggunakan tanaman secara langsung karena akan beresiko merusak komputer.

\section{2) Non-visual connection with nature}

Pola yang mengandalkan indera pendengar, pencium, peraba, dan perasa dalam merasakan ruang yang berhubungan dengan alam. Ruang dengan bukaan jendela memungkinkan suara dan aroma hujan masuk dalam ruang. Suara alam seperti suara burung, desiran ombak, dan gemerisik tanaman dari bukaan atau audio speaker juga dapat diterapkan dalam ruang. Material bertekstur kasar, tanaman dan kolam yang dapat diakses secara langsung oleh pengguna dapat meningkatkan koneksi pengguna dengan alam. 

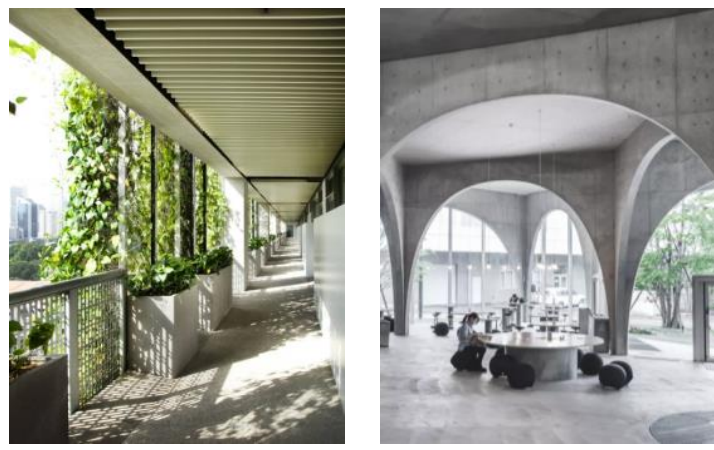

Gambar 3. Contoh penerapan pattern non-visual connection with nature dengan (kiri) tanaman yang dapat diakses secara langsung dan (kanan)

bukaan tempat masuknya suara dan aroma dari alam. Sumber: http://pinterest.com

Pola dapat diterapkan pada semua elemen interior kecuali elemen pencahayaan dan informasi. Kedua elemen interior ini mengandalkan visual individu untuk merasakan ruang sehingga tidak sesuai dengan prinsip pola nonvisual connection with nature yang menggunakan indera peraba, pencium, pendengar, dan perasa.

\section{3) Non-rhytmic sensory stimuli}

Pola berkaitan dengan alam yang bersifat acak dan berlangsung sebentar sehingga tidak disadari oleh pengguna ruang tetapi dapat menciptakan suasana yang segar, menarik, dan semangat. Gerakan tanaman yang tertiup angin, gerakan awan membentuk bayangan, refleksi air, dan kilauan logam tidak disadari oleh penggina ruang namun dapat menstimulasi ingatan akan lingkungan alam.
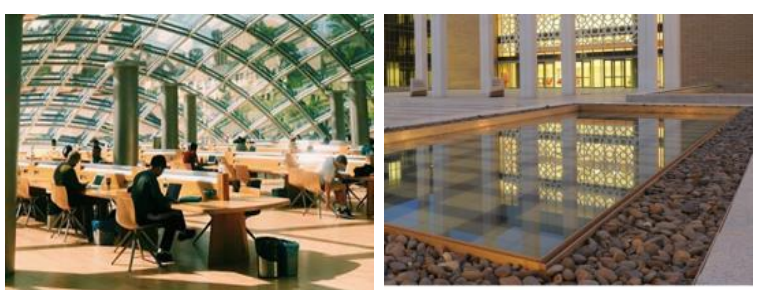

Gambar 4. Contoh penerapan non-rhytmic sensory stimuli dengan (kiri) pergerakan awan dengan bayangan acak dan (kanan) refleksi air yang tidak dapat diprediksi oleh pengguna ruang. Sumber: http://pinterest.com

Pola dapat diterapkan pada semua elemen interior di semua ruang dalam fasilitas pendidikan asalkan ada gerakan, suara, kilauan, atau aroma yang tidak dapat diperkirakan atau disadari oleh pengguna ruang.

\section{4) Thermal and airflow variability}

Pola ini berkaitan dengan pegerakan udara, suhu, dan kelembapan dengan sifat dinamis dan bervariasi menyerupai kondisi asli di alam. Bukaan jendela dan ventilasi memungkinkan udara mengalir dengan baik. Sunshade dan louvre dapat dimanfaatkan untuk mengontrol intensitas sinar matahari sehingga suhu termal ruangan tetap terjaga.

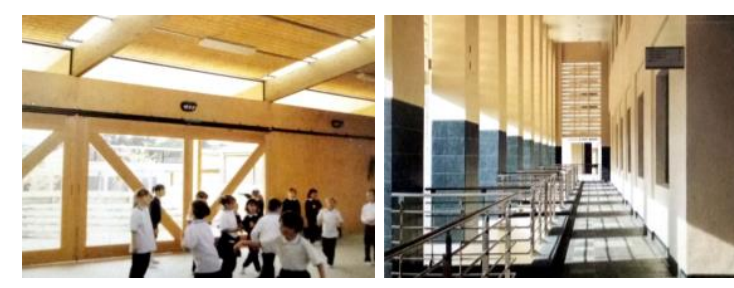

Gambar 5. Contoh penerapan pattern thermal and airflow variability dengan jendela ventilasi (kiri) dan bukaan dengan sunshade (kanan) Sumber: http://pinterest.com

Pola ini dapat diterapkan pada semua elemen interior kecuali elemen pendukung, pemajang penyimpan, permukaan kerja, dekorasi, dan informasi. Keempat

elemen interior ini tidak berhubungan dengan sistem penghawaan dalam interior sehingga tidak sesuai dengan pola thermal \& airflow variability.

\section{5) Presence of water}

Pola ini memanfaatkan unsur air dalam ruang sehingga memberikan suasana nyaman dan menenangkan bagi terhadap pengguna ruang fasilitas pendidikan tinggi. Bentuk penerapan pola ini antara lain: bukaan tempat akses air hujan dalam ruang, waterwall, akuarium, kolam dan dekorasi air mancur dalam ruang
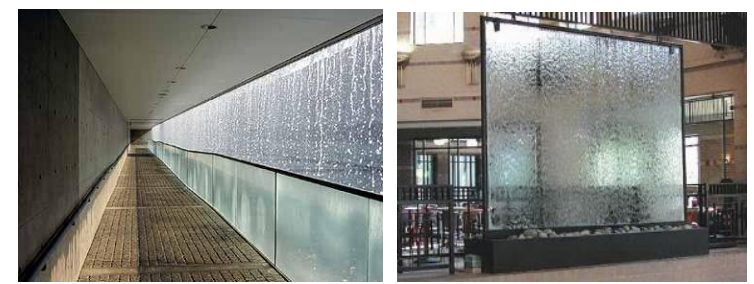

Gambar 6. Contoh penerapan pattern presence of water dengan (kiri) bukaan akses air hujan dan (kanan) waterwall. Sumber: http://pinterest.com

Pola dapat diterapkan pada semua elemen interior kecuali elemen pendukung. Semua penerapan pola biophilic design ke-5 ini perlu mempertimbangkan risiko rusaknya komputer, koleksi buku, atau benda seni jika terkena air.

\section{6) Dynamic and diffuse lighting}

Pola berkaitan dengan pergerakan cahaya alami karena perbedaan waktu yang bersifat dinamis dan menyebar dalam ruang sehingga timbul kontras area terang dan gelap. Bentuk penerapan pola ini misalnya pencahayaan dengan kesan dinamis, skylight dan jendela sebagai akses cahaya matahari.
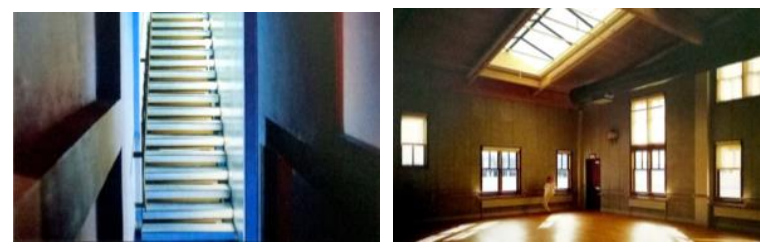

Gambar 7. Contoh penerapan pattern dynamic and diffuse lighting dengan (kiri) pencahayaan dari bawah memberi kesan dinamis dan (kanan) skylight dan jendela tempat masuk sinar matahari. Sumber: http://pinterest.com 
Pola dapat diterapkan pada semua elemen interior. Penerapan pola ini dapat dilakukan di semua ruang fasilitas pendidikan menyesuaikan aktivitas pengguna ruang.

\section{7) Connection with natural system}

Pola ini menghubungkan interior dengan sistem alam yang selalu berubah agar pengguna ruang dapat berinteraksi dengan alam. Bentuk penerapan pola ini misalnya hadirnya tanaman atau kolam ikan dalam ruang, sistem pencahayaan dengan siklus diurnal, dan penggunaan material yang dapat lapuk atau berkarat. Pola dapat diterapkan pada semua elemen interior. Pola biophilic design ke-7 ini dapat diterapkan di semua ruang dalam fasilitas pendidikan.

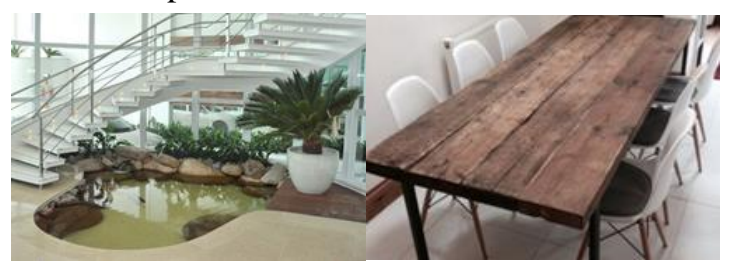

Gambar 8. Contoh penerapan pattern connection with natural system dengan (kiri) kolam yang dapat diamati pergerakan ikan dan (kanan) material kayu alami yang dapat lapuk. Sumber: http://pinterest.com

\section{8) Biomorphic forms and patterns}

Pola ini meniru atau menstilasi bentuk alam dalam bentuk dan motif untuk elemen pembentuk dan pengisi ruang untuk menghadirkan suasana alam. Penerapan pola ini dapat dilakukan misalnya dengan menerapkan bentuk organis, hewan, tumbuhan, atau ombak pada elemen pembentuk dan pengisi interior.

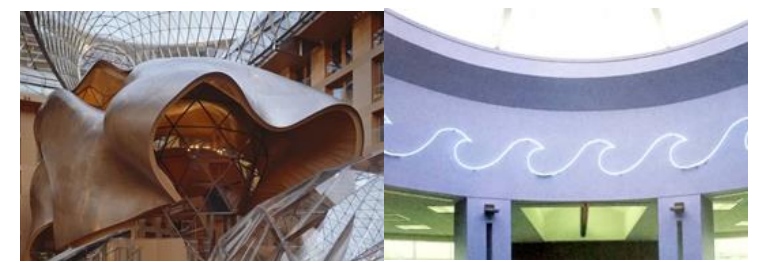

Gambar 9. Contoh penerapan pattern biomorphic forms and patterns dengan (kiri) bentuk organis pada elemen pelingkup dan (kanan) lampu berbentuk ombak. Sumber: http://pinterest.com

Pola ini dapat diterapkan pada semua elemen interior di seluruh ruang fasilitas pendidikan. Penerapan pola ke- 8 biophilic design ini dilakukan dengan cara menerapkan bentuk alam seperti tumbuhan dan hewan dalam bentuk struktur maupun motif bahan pelapis.

\section{9) Material Connection with Nature}

Pola yang menggunakan material alami yang mengalami perubahan dari waktu ke waktu sehingga dapat menggambarkan lingkungan alam. Material yang dapat diterapkan pada pola ini misalnya kayu, bambu, rotan, daun kering dan rotan alami yang dapat mengalami perubahan seiring berjalannya waktu.

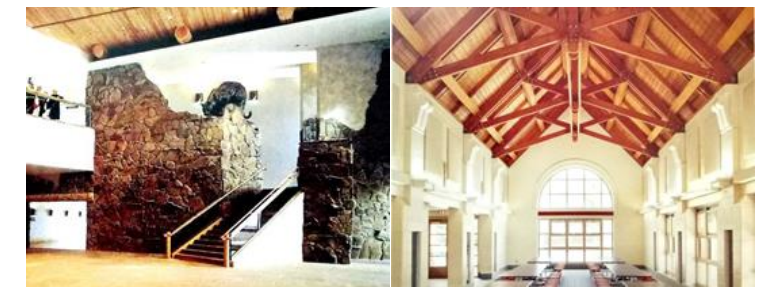

Gambar 10. Contoh penerapan pattern material connection with nature dengan (kiri) dinding batu dan (kanan) plafon kayu. Sumber: http://pinterest.com

Pola ini dapat diterapkan pada semua elemen interior di semua ruang fasilitas pendidikan tinggi. Penerapan pola ke-9 biophilic design ini dilakukan dengan cara memanfaatkan material alami seperti kayu, batu, rotan, dan bambu untuk struktur maupun pengisi interior.

10) Complexity and order

Pola ini menerapkan bentuk simetri dan geometri yang berulang dengan skala yang sama atau berbeda sehingga individu dapat lebih memahami ruang. Penerapan pola ini dilakukan misalnya dengan menggunakan patra dan bentuk geometris dan fractal serta penyusunan simetris.

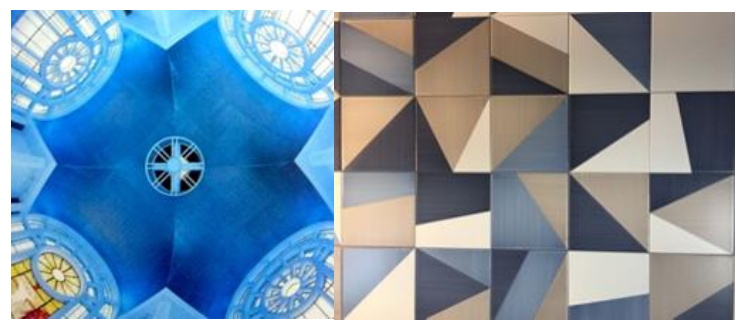

Gambar 11. Contoh penerapan pattern complexity and order dengan (kiri) plafon berbentuk simetris dan (kanan) pola lantai geometris berulang. Sumber: http://pinterest.com.

Pola dapat diterapkan pada semua elemen interior di semua ruang dalam fasilitas pendidikan asalkan ada bentuk dan motif yang berulang dan berurutan memunculkan bentuk geometris fractal.

\section{1) Prospect}

Pola memberikan pandangan luas, terbuka, dan terang pada ruang agar pengguna dapat merasakan keberagaman dalam interior bangunan perguruan tinggi. Bentuk penerapan pola ini misalnya: plafon tinggi, banyak bukaan pada dinding, partisi transparan, ruangan terang, dan pandangan yang luas.

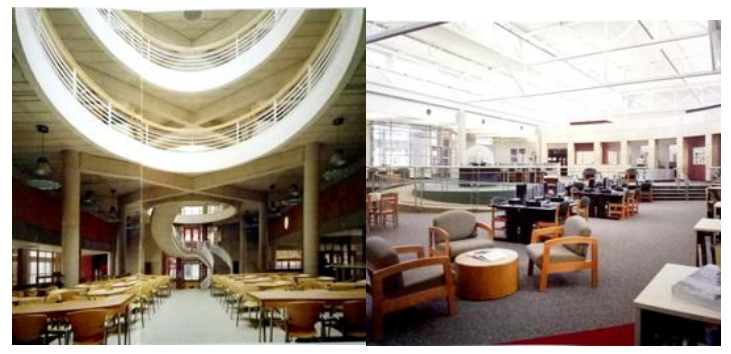

Gambar 12. Contoh penerapan pattern prospect dengan (kiri) plafon tinggi dengan void dan (kanan) pencahayaan terang dan tanpa sekat partisi. Sumber: http://pinterest.com

Pola dapat diterapkan pada semua elemen interior di semua ruang di fasilitas pendidikan. Penerapan elemen ini dilakukan dengan mendukung pemandangan ruang yang luas, terang, dan terbuka. 
1) Refuge

Pola ini membuat area tertutup atau membatasi pandangan dari luar area agar pengguna dapat merasa aman dan terlindungi. Bentuk penerapan pola ini antara lain plafon yang rendah, pandangan terbatas, area privat untuk membaca, serta meja bersekat.

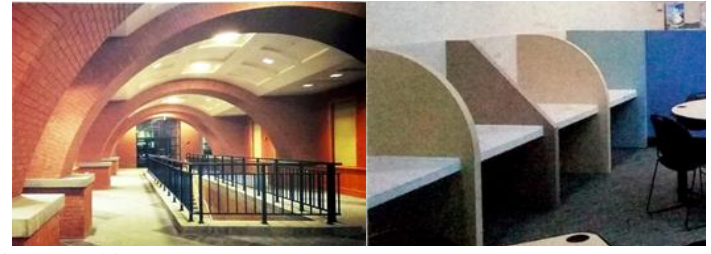

Gambar 13. Contoh penerapan pattern refuge dengan (kiri) plafon rendah dan (kanan) meja bersekat menciptakan area privat. Sumber: http://pinterest.com

Pola dapat diterapkan hampir pada semua elemen interior kecuali informasi karena elemen ini tidak beruhubungan dengan menjaga perlindungan bagi individu. Penerapan pola biophilic design ke-12 dapat dilakukan di semua ruang fasilitas pendidikan tinggi khususnya ruang kelas, ruang rapat, dan area baca perpustakaan.

2) Mystery

Pola memberikan rasa kagum dan ingin tahu akan sensasi yang dirasakan dalam ruang seperti pergerakan dinamis dan perubahan dari waktu ke waktu. Penerapan pola ini misalnya bidang pijakan berkelok, jendela terbatas, bentuk ruangan melengkung, serta dekorasi infinity glass.

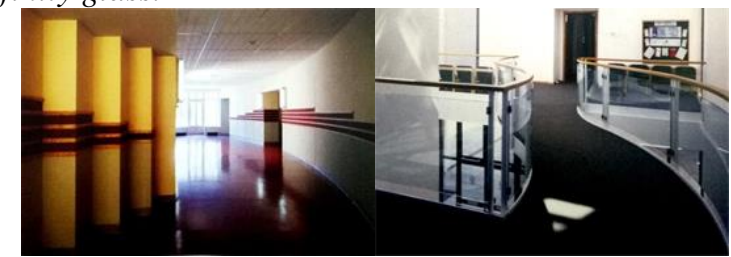

Gambar 14. Contoh penerapan pattern mysterydengan (kiri) ruangan berbentuk melengkung dan (kanan) lantai berkelok. Sumber: http://pinterest.com

Pola ini dapat diterapkan pada semua elemen interior dalam semua ruang fasilitas pendidikan tinggi. Penerapan pola ini dilakukan dengan cara memberi benda, cahaya, suara, gerakan, dan aroma alami tanpa menunjukkan sumber atau wujudnya secara keseluruhan.

14) Risk/Peril

Pola memberikan rasa bahaya atau ancaman tetapi tetap merasa terlindungi agar pengguna ruang dapat meningkatkan keingintahuan, kewaspadaan, dan kekaguman. Bentuk penerapan pola ini antara lain lantai dan dinding kaca, lantai dikelilingi kolam, akuarium pada plafon, atau pagar rendah di tempat tinggi.
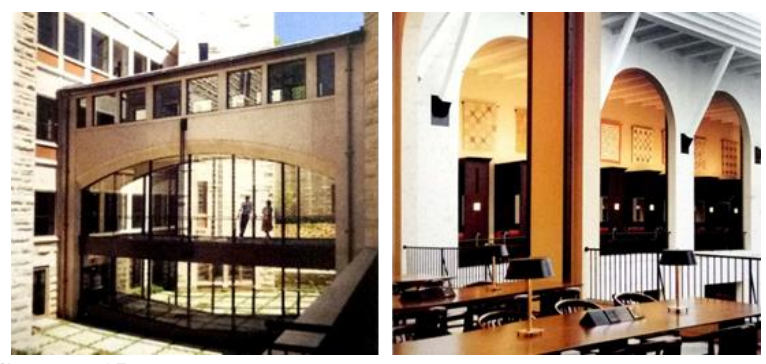

Gambar 15. Contoh penerapan pattern risk/peril dengan (kiri) dinding kaca dan (kanan) pagar rendah pada ketinggian. Sumber: http://pinterest.com
Pola dapat diterapkan pada semua elemen interior kecuali elemen pencahayaan dan informasi. Penerapan pola ini perlu menjaga pengguna ruang tetap aman walaupun desain interior terlihat berbahaya sehingga individu merasa bersemangat dan terpacu untuk beraktivitas.

\section{REKOMENDASI TERAPAN BIOPHILIC DESIGN PADA OBJEK STUDI KASUS}

Gedung P1 dan P2 Universitas Kristen Petra Surabaya sampai saat ini (Mei 2018) belum dapat beroperasional karena bagian interior belum selesai. Studi kasus dalam penelitian ini bertujuan untuk memberi rekomendasi desain interior Gedung P1 dan P2 dengan pendekatan biophilic design. Rekomendasi ini meliputi pattern biophilic design apa saja yang dapat diterapkan dalam interior ruang fasilitas pendidikan tinggi beserta alasannya.

Terdapat beberapa pattern biophilic design yang dapat diterapkan pada objek studi kasus. Berikut ini adalah rekomendasi terapan biophilic design pada Gedung P1 dan P2 Universitas Kristen Petra Surabaya:

\section{1) Visual connection with nature (P1)}

Gedung P1 dan P2 yang memiliki konsep desain green building cocok menerapkan pattern visual connection with nature karena kehadiran tanaman dalam ruang serta pemandangan hijau dapat memberi perasaan bahagia individu. Bentuk terapan pattern ini antara lain:

- Pemandangan pepohonan atau lapangan rumput

- Banyak bukaan pada dinding atau plafon (void)

- Pemanfaatan tanaman dalam ruang

- Lukisan atau karya seni menunjukkan visual alam

- Perabot dengan wadah tanaman atau akuarium

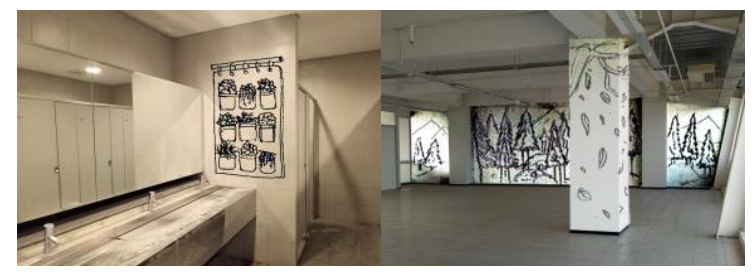

Gambar 16. Penerapan pattern visual connection with nature (kiri) vertical garden di toilet dan (kanan) lukisan dan wallpaper nuanasa alam di ruang studio. Sumber: dokumen pribadi

2) Non-visual connection with nature (P2)

Konsep ruang terbuka dari arsitektur gedung P1 dan P2 dapat melengkapi terapan pattern non visual connection with nature ini. Banyaknya bukaan memungkinkan pengguna ruang merasakan alam menggunakan indera pendengar, peraba, dan pencium dari dalam interior bangunan. Suasana alam dapat dihadirkan secara multisensori dengan beberapa cara sebagai berikut:

- Jendela dan celah bangunan tempat masuk suara lingkungan (suara burung dan air hujan).

- Tekstur kasar material batu atau kayu .

- Tanaman dalam ruang yang dapat mengeluarkan bau wangi atau pengharum ruang otomatis. 


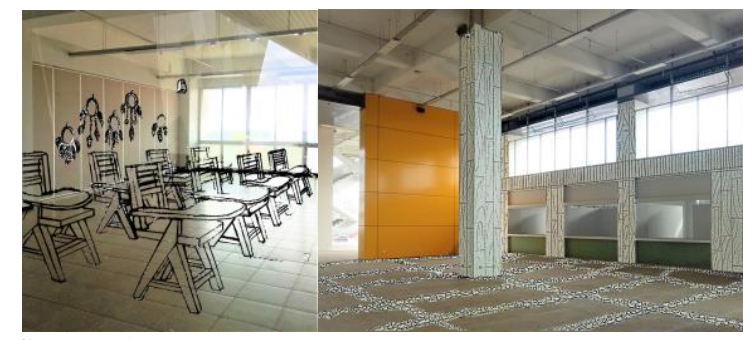

Gambar 17. Penerapan pattern non-visual connection with nature dengan (kiri) dekorasi bulu hewan dan kursi bertekstur kayu di ruang kelas dan (kanan) lantai batu serta kayu pelapis di kantin. Sumber: dokumen pribadi.

\section{3) Thermal and airflow variability (P4)}

Desain arsitektur gedung P1 dan P2 mendukung penerapan pattern thermal \& airflow variability ini. Bentuk gedung yang tipis dan memanjang dapat memaksimalkan sirkulasi udara alami (cross ventilation). Kedua gedung ini berbentuk miring melewati satu sama lain sehingga tercipta celah pada bagian tengah sebagai saluran angin yang mengalir ke interior ruang. Posisi miring bangunan ke arah utara dan selatan memungkinan tiap lantai tidak menyerap sinar matahari secara langsung sehingga meminimalkan beban AC.

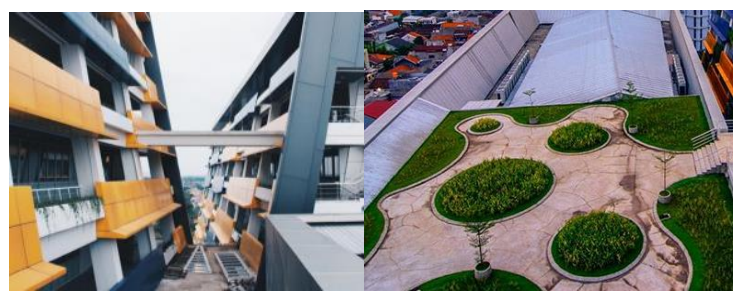

Gambar 18. Penerapan pattern thermal and airflow variability dengan (kiri) celah antar bangunan tempat aliran udara masuk dan (kanan) rooftop garden sebagai penghalang termal. Sumber: dokumen pribadi.

\section{4) Material connection with nature (P9)}

Penerapan pattern material connection with nature ini dapat diterapkan pada lantai dan perabot dalam ruang kelas, ruang staf, atau plaza. Material alam dapat menghadirkan alam dalam ruang dengan beberapa cara sebagai berikut:

- Lantai batu agar tidak licin.

- Dekorasi atau kap lampu dari daun atau rotan .

- Kursi, meja, dan rak buku yang terbuat dari kayu.

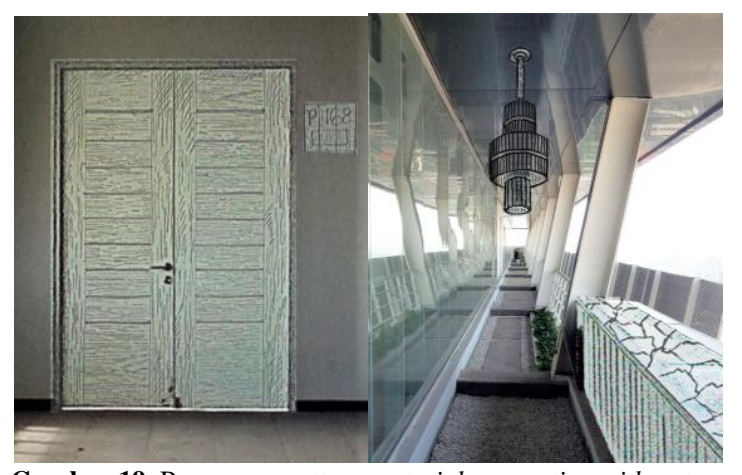

Gambar 19. Penerapan pattern material connection with nature dengan (kiri) pintu dan signage kayu yang masih terlihat guratan dan (kanan) lampu rotan dan lantai batu di koridor. Sumber: dokumen pribadi.
5) Complexity and Order (P10)

Pattern ke sembilan ini cocok diterapkan di gedung P1 dan P2 karena bentuk arsitekturnya sendiri sudah banyak menerapkan pattern ini. Kompleksitas dari bentuk-bentuk berulang dapat meningkatkan kinerja dan kretivitas pelajar. Bentuk penerapan pattern antara lain:

- Lantai dengan pola geometris berulang.

- Dekorasi dan signage patra segitiga kompleks.

- Dinding mosaik geometris dan jendela berpola.

- Perabot berbentuk patra geometris.

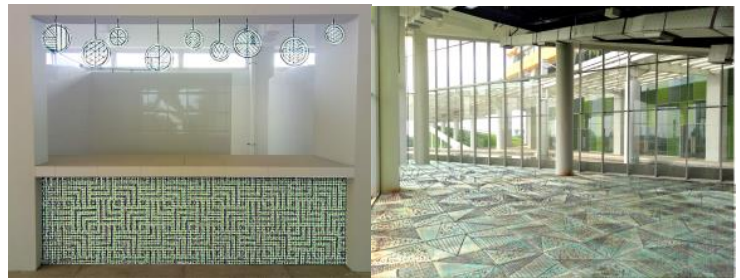

Gambar 20. Penerapan complexity and order dengan (kiri) kios kantin dari mosaik dan dekorasi patra geometris beraturan dan (kanan) lantai geometris dan warna berulang. Sumber: dokumen pribadi.

6) Refuge (P12)

Plaza sebagai tempat sosial bagi mahasiswa membutuhkan area privat untuk belajar, beristirahat, atau sekedar berbincang. Kebutuhan akan area 'perlindungan' ini dapat dilakukan dengan beberapa cara, antara lain:

- Lantai yang berbeda warna dari area lain

- Plafon yang lebih rendah

- Sofa atau meja bersekat

- Pencahayaan yang tidak terlalu terang
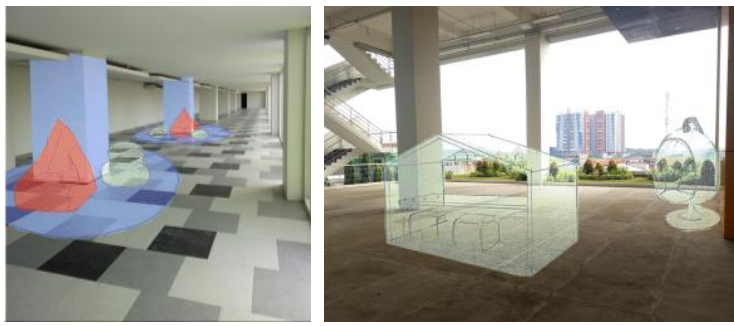

Gambar 21. Penerapan pattern refuge dengan (kiri) area privat dari lantai dan pelingkup yang berbeda warna dan (kanan) area baca dengan perabot tertutup sebagian. Sumber: dokumen pribadi.

\section{7) Risk/Peril (P14)}

Penerapan pattern risk/peril ini dapat memicu kinerja individu karena munculnya kesenangan tersendiri dari desain yang terlihat berbahaya. Pengguna ruang juga menjadi lebih ingin tahu dan waspada terhadap lingkungan sekitar. Pola ini dapat diterapkan dengan beberapa cara sebagai berikut:

- Pagar pendek di ruang tinggi agar tetap aman

- Jendela dari plafon hingga lantai

- Bentuk perabot dan dekorasi yang terlihat berbahaya

- Taman di ujung bangunan bertingkat 


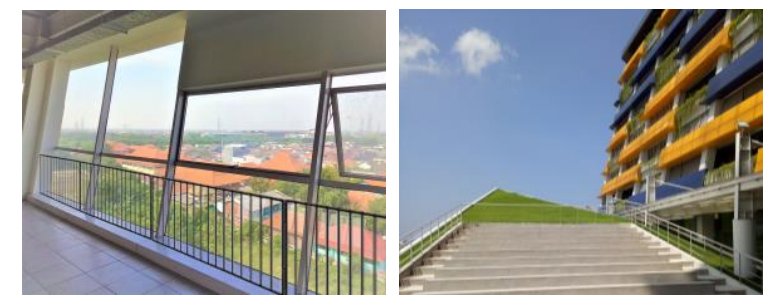

Gambar 22. Penerapan pattern risk/peril dengan (kiri) jenela miring dari plafon hingga lantai diberi pagar pendek agar lebih aman dan (kanan) taman di ujung ketinggian Sumber: dokumen pribadi

\section{SIMPULAN}

Hasil penelitian ini mengungkapkan bahwa identifikasi penerapan biophilic design pada interior fasilitas pendidikan tinggi dapat dilakukan dengan menerapkan semua 14 pola biophilic design. Penerapan 14 pattern biophilic design tersebut hanya sembilan pola yang dapat diaplikasikan pada 9 elemen interior (pattern 2, 4, 5, 12 dan 14 tidak dapat diterapkan pada elemen tertentu). Hasil identifikasi juga menunjukkan semua penerapan dapat dilakukan di area publik tetapi hanya sebagian saja yang boleh pada area penunjang dan akademik. Penerapan biophilic design harus tetap memperhatikan lokasi peletakkan tanaman atau fitur air yang berisiko merusak koleksi buku atau alat elektronik dalam ruang kelas, perpustakaan, laboratorium, dan ruang staf. Bukaan yang besar dapat menjadi akses pemandangan dan aliran udara dari dalam ruang, tetapi bukaan juga dapat menyebabkan cahaya matahari masuk terlalu banyak sehingga menimbulkan silau atau memantul pada layar komputer.Hasil analisis penerapan 14 pola biophilic design pada interior fasilitas pendidikan tinggi menunjukkan semua pola biophilic design dapat diterapkan pada interior perguruan tinggi meskipun tidak semua elemen interior dapat menerapkan semua pola.

Rekomendasi terapan pola biophilic design pada objek studi kasus Gedung P1 dan P2 Universitas Kristen Petra telah disimulasikan dengan menerapkan semua 14 pola biophilic design pada interior ruang melalui ide-ide sketsa konseptual. Rekomendasi yang paling berpengaruh yaitu pada penerapan pattern 1, 8, 9, dan 10 . Keempat pattern ini menambahkan bentuk dan material organis pada ruang sehingga pengguna akan lebih merasakan alam karena bentuk arsitektur eksisting yang terlalu kaku. Sebenarnya arsitektur bangunan gedung P1 dan P2 secara tidak sengaja sudah menerapkan pattern biophilic design misalnya pada pattern thermal \& airflow variability (P4), presence of water (P5), dan prospect (P11).

\section{REFERENSI}

[1] W. Browning, C. Ryan, \& J. Clancy, 14 Patterns of Biophilic Design. New York: Terrapin Bright Green (2014) 6.

[2] M. Subroto, J. Priatman, \& J. Rahardjo, "Analisa kesadaran biophilia pada mahasiswa calon pengguna gedung P1 dan P2 Universitas Kristen Petra
Surabaya," dalam Dimensi Utama Teknik Sipil, Vol. 2, Surabaya: Universitas Kristen Petra (2015) 3.

[3] A. Syarief, "Eksposisi riset desain: membangun tradisi riset melalui pemahaman atas kontekstualitasi pengetahuan desain," dalam Seminar Nasional Seni dan Desain, Surabaya: FBS Unesa (Oktober 2017) 4-5.

[4] L. Moleong, Metodologi Penelitian Kualitatif (Edisi Revisi). Bandung: Rosdakarya (2017) 34.

[5] A. Zakiyaturrahmah, R. Nugroho, L. Pramesti, "Penerapan teori biophilic design dalam strategi perancangan sekolah alam sebagai sarana pendidikan dasar di Karanganyar," dalam Arsitektura, Vol. 15, Surakarta: Universitas Sebelas Maret (2017) 407.

[6] J. Priatman, "Konsep desain biophilia sebagai dimensi hijau pada arsitektur empatik," dalam Seminar Nasional Menuju Arsitektur berEmpati Surabaya: Universitas Kristen Petra (2012) 38-39.

[7] M. Febriana, Identifikasi Pemahaman Biophilic Design dalam Konteks Desain Interior. Surabaya: Universitas Kristen Petra (2016) 89-131.

[8] Menteri Pendidikan Nasional. Lampiran Peraturan Menteri Pendidikan Nasional, no. 24 tahun 2007 (Juni 2007) 1.

[9] A. Sully. Interior Design Theory Process. London: A\&C Black Publishers (2012) 27-54.

[10] Badan Standar Nasional Pendidikan. Rancangan Standar Sarana dan Prasarana Pendidikan Tinggi Program Pascasarjana Dan Profesi (Juli 2011) 1-5.

[11]D. J. Neuman. Buildinng Type Basics for: College and University Facilities. S. A. Kliment, Ed. Canada: Wiley (2003) 78-275. 